\title{
Procesos de tradicionalización en el corrido de "Valentín de la Sierra": del texto noticiero al novelesco
}

WENDY MoRALES PRADO

El Colegio de Morelos

\section{Introducción}

En 1926, en concomitancia con los últimos años de la Revolución Mexicana, estalló la Guerra Cristera en una amplia zona de la República, como se sabe, ambos movimientos tuvieron honda repercusión en nuestro país. El alzamiento cristero lo ocasionó una ley promulgada en el gobierno de Plutarco Elías Calles que buscaba limitar o suprimir de manera radical la participación de la Iglesia católica en la vida pública, ley, que, como podría suponerse, fue rechazada por la población. Una importante región conformada por los estados de Guanajuato, Jalisco, Querétaro, Aguascalientes, Nayarit, Colima y parte de los estados de San Luis Potosí y Zacatecas tomó parte activa en el movimiento armado que defendía su derecho a la libertad de culto. ${ }^{1}$

En el pueblo de Valparaíso, Zacatecas, sucedió la historia de un joven cristero que pertenecía a las huestes de Pedro Quintanar. Aquel hombre era "Valentín Ávila, del Rancho de los Landa en Huejuquilla el Alto, Jalisco, fusilado en febrero de 1928, y quien formaba parte de las fuerzas cristeras encabezadas por Pedro Quintanar que se levantaron contra el gobierno en 1926, en la parte occidental de Zacatecas" (González, 2015: 270). En cuanto

\footnotetext{
${ }^{1}$ Una versión preliminar de este trabajo se presentó en el seminario de Literatura Popular y Tradicional a cargo de Aurelio González en el Centro de Estudios Lingüísticos y Literarios del Colegio de México.
} 
a la autoría del texto que canta las virtudes de Valentín, hay distintos datos que, no obstante, apuntan al mismo origen. Antonio Avitia en su conocido estudio El corrido histórico mexicano afirma que la composición pertenece a la pluma de Lidio Pacheco, de quien se tienen pocas noticias, por lo que el texto suele ser atribuido al cantante Luis Pérez Meza (Avitia, 1998: 68), también conocido como El trovador del Campo. El historiador Jean Meyer, con mayor precisión, asegura que los autores son los hermanos Pacheco - uno de ellos es Lidio-, campesinos de Huejuquilla el Alto, Jalisco y que el corrido Valentín de la Sierra contaba la historia de un traidor; así, según Meyer, el que conocemos actualmente es una parodia que las fuerzas federales hicieron de la historia original (Meyer, 1986: 160).

Al parecer, la autoría del corrido, por los datos que los especialistas han podido aportar, manifiesta imprecisiones, e incluso el sentido primigenio del corrido es dudoso, pues para unos, aquella pieza constituyó inicialmente una burla. Sin demeritar la relevancia que proporcionan los datos históricos y la autoría del corrido, es evidente que el alcance social que ha tenido la composición de Valentín de la Sierra en la canción popular mexicana está lejos de basarse en la maestría de un autor o la simplificación de un hecho histórico. El punto de vista que se quiere resaltar aquí es que, incluso a través de los registros sonoros que cantantes de música vernácula han difundido masivamente, el éxito persistente a través de generaciones y el arraigo social del corrido se debe a su índole tradicional, la cual destaca la identificación social de un personaje que representa valores y vivencias trascendentes para oyentes y transmisores ; a Valentín de la Sierra "se le atribuye el valor a toda prueba y la dignidad ante la muerte" (González, 1999: 93). Por eso la autoría, en tal sentido, tampoco es relevante, en tanto el texto pertenece a la comunidad que se ha apropiado de él y lo dota de características particulares. Tal como señala Aurelio González, “en la zona del Bajío [...] los corridos de la Guerra Cristera sucedida en la segunda década del siglo (1925-1932) [...] siguen teniendo vigencia y la comunidad los recuerda y establece una identificación con sus personajes y valores a pesar de haber dejado de 
existir el clima épico en el cual nacieron" (González, 1999: 94). Siguiendo el razonamiento que el investigador ha vertido en numerosos trabajos, el corrido, como expresión de la balada hispánica, se caracteriza, según lo estableció Menéndez Pidal, como literatura tradicional, en tanto se transmite de una generación a otra, su soporte es la memoria y vive en variantes, pues los miembros de la comunidad se sienten libres de cambiar aquel texto, según las condiciones abiertas que presenta. Por otra parte, gracias a singularidades propias:

El texto es una forma de discurso que la comunidad identifica por una serie de características formales [saludo introductorio, división estrófica y despedida] y temáticas [corridos de rebeldes, de revolucionarios, de tragedias, de caballos], las cuales cuando se identifica con ellas puede recrear y refuncionalizar para adaptar el texto a nuevas condiciones sociales (González, 1999: 95).

En el presente trabajo ofrezco un corpus con nueve versiones del corrido de Valentín de la Sierra. Como se podrá apreciar en la lista que se encuentra líneas abajo, las primeras tres versiones se tomaron de antologías, las cuales indican los datos de recolección respectivos; la cuarta versión es una reconstrucción facticia, y las versiones restantes corresponden a interpretaciones realizadas por cantantes de música vernácula en producciones musicales, cuyas grabaciones oscilan entre los años 1968 y 2005. Al final de este trabajo se aportan los datos completos de cada versión; no obstante, en la siguiente lista se indican los datos generales de las variantes del corpus para identificarlas y poder así referirnos a ellas empleando sólo el número arábigo que se les ha asignado:

Versión 1 Recolección in situ en Huejuquilla el Alto, Jalisco, por Irene Vázquez Valle y José de Santiago Silva (2002).

Versión 2 Recolección en Valparaíso, Zacatecas, por Cuauhtémoc Esparza Sánchez (Avitia, 1998). 
Versión 3 Recolección en Dolores Hidalgo, Guanajuato, por Armando de María y Campos (Avitia, 1998).

Versión 4 Versión reconstruida de Antonio Avitia Hernández (1998).

Versión 5 Procede de Dolores Hidalgo, Guanajuato, comunicado por Quintín Zamora, ciego. Recolección realizada el 18 de diciembre de 1950. En Mendoza, 1954.

Versión 6 Antonio Aguilar (1968).

Versión 7 Vicente Fernández (2005).

Versión 8 Lucha Villa (2002).

Versión 9 Amparo Ochoa (1995).

Naturalmente, la versión más larga del corpus recopilado es la facticia de Antonio Avitia, que comprende veinte estrofas y se identifica con el número 4. Del cuerpo de versiones que habitaron la memoria comunitaria, sigue la segunda versión con dieciocho estrofas. Las más pequeñas y versátiles son las versiones 3 y 5 que tienen ocho, y la que interpreta Antonio Aguilar, identificada con el número 6.

Para analizar el corrido, dividí la historia en seis secuencias constantes en cada variante. Analizo aquí los cambios de estas unidades menores para mostrar las reformulaciones del texto, así como su paso de una finalidad noticiera a la novelesca que evidencia la voluntad de creación poética sobre el texto, propia de los textos tradicionales. Estas creaciones, mediante distintos procedimientos en cada variante, modifican aspectos determinados del corrido, ya desarrollando, ya intensificando o añadiendo matices mediante descripciones, ponderaciones, etc. Incluso, no obstante la alteración del orden de determinadas secuencias, se mantiene intacto el sentido total de la pieza. Me interesa recalcar que, aunque estas variantes no fueron grabadas por mí en comunidades determinadas, las estructuras narrativas presente en el corrido continúan comportándose como textos tradicionales, 
así pues, la historia de un héroe trágico se mantiene vigente y vive en variantes interpretadas por representantes de la canción ranchera contemporánea.

Ahora bien, es indispensable aclarar las implicaciones de tomar en cuenta para este estudio las variantes de cantantes de música vernácula mexicana. Este tipo de divulgadores que tienen más oyentes y que mediante sus grabaciones trascienden fronteras espacio-temporales, actúan como enunciadores privilegiados que, no obstante, pertenecen a la cadena de transmisión de tipo tradicional, con las mismas oscilaciones entre variación y conservación. ${ }^{2}$ Por lo que no es de sorprender que entre los cuatro cantantes que se analizan existan diferencias significativas que se irán comentando conforme aparezcan en el análisis.

Si bien la unidad formal del corrido es la cuarteta $-\mathrm{y}$ en ese sentido, Valentín de la Sierra no es la excepción,$-{ }^{3}$ conformada por tres octosílabos y un último verso con doce sílabas, las secuencias que analizo están determinadas por un criterio narrativo de unidades de sentido o de acción que, en ocasiones, sobrepasan una estrofa.

Consideré indicar cambios a nivel léxico que encontré y otros más que advertí en los versos, pues esas alteraciones manifiestan procesos de interés, a pesar de que formen parte de estructuras menores de las que, en principio, me propuse considerar.

Las secuencias narrativas presentes en las versiones del corrido se mencionan en seguida, y lleva ese mismo orden el análisis:

1. Presentación del corrido.

2. Valentín cae presa del gobierno.

3. Los representantes de la autoridad formulan tres preguntas al héroe, buscando que delate a sus seguidores.

4. La negativa de Valentín, es acompañada de cierta bravuconería.

\footnotetext{
${ }^{2}$ Véase González (2015: 75).

${ }^{3}$ Aunque en la transcripción completa conservé los quintetos, tal y como aparecen en las versiones consignadas por Antonio Avitia Hernández.
} 
5. Se produce la despedida en la que el héroe se encomienda a la Virgen de Guadalupe.

6. Cierre del corrido.

\title{
Desarrollo
}

\section{Presentación del corrido}

La entrada muestra pocos cambios entre las variantes. Contiene una identificación genérica y formulaica. En esta primera estrofa, se presenta la voz narrativa en primera persona. La señal que informa que se cantará un corrido apercibe a quien escucha de que la historia que viene a continuación pertenece a uno de los géneros de mayor prestigio de la canción mexicana.

No obstante, en su primera estrofa las versiones 1 y 3 privilegian el aspecto directo y personal, pues comienzan con "Voy a cantar unos versos". Esas mismas versiones tienen un verso distinto "del valiente Valentín". La interpretación número 5 tiene una ligera variante en el mismo tercer verso: en "llamádose". La variante cantada por Antonio Aguilar presenta una leve verbalización, es decir, imitación del modo de habla popular:

\author{
Voy a cantar un corrido \\ de un amigo de mi tierra \\ llamábase Valentín \\ que fue fusilao y colgao en la Sierra. \\ (Versión 6)
}

Otra verbalización aparece en la versión número 2 con las palabras "afusilao", " pa"', y, más adelante, "trai", todo ellos, modos cotidianos de enunciación popular.

Además, hay que notar un reconocimiento del emisor y el héroe del corrido como individuos de la misma comunidad - son amigos y de la misma tierra - por lo que, seguramente, comparten los valores que expresará la composición. Por otra parte, que 
el corrido no mencione el nombre de Valentín Ávila y diga que es Valentín de la Sierra desde un principio es un indicio de caracterización de un héroe despojado de su individualidad, presentado como arquetipo del hombre mexicano del campo. Por supuesto, el nombre Valentín identifica a la persona históricobiográfica que da pie al corrido, pero este dato coincide con el mensaje inequívoco de un hombre valeroso, osado, desafiante, que destaca entre otros seres ruines.

No es ocioso mencionar que el corrido desde sus inicios anticipa el final desgraciado de su protagonista: el transmisor incorpora suspenso que acrecienta el interés de quienes escuchan. ¿Por qué el cantante quiere contar la historia de un amigo fusilado y colgado?

\section{Valentín cae en manos del gobierno}

La primera estrofa de esta secuencia no presenta variaciones en las versiones que integran el corpus, debido a que contiene dos asuntos fundamentales: el primero marca nuevamente la vinculación emotiva del transmisor con el hecho desgraciado - peripecia que desencadena la narración - y se establece la dicotomía que pone al héroe ante sus enemigos: en este punto, el antagonista es una entidad impersonal. La estrofa que plantea el antagonismo se encuentra en todas las variantes sin modificación:

No me quisiera acordar, era una tarde de invierno, cuando por su mala suerte cayó Valentín en manos del gobierno.

Efectivamente, el "gobierno" es la contraparte malvada de la historia; esta oposición asocia el pueblo con los buenos y al gobierno opresor, como los malos. Los agentes del gobierno, como entidad ajena y negativa, no tienen nombre, ni una identificación posible que los ligue con el hecho porque su individualidad carece de relevancia: lo que importa es consignar lo que sucedió al 
personaje principal. Como marca tradicional, cada comunidad determina a quién le interesa caracterizar y en este corrido, es a Valentín.

Con todo, en las referencias al espacio o los lugares en donde se desarrolló la acción se observan imprecisiones: las estrofas de las versiones 1,3 y 5 detallan circunstancias, lugares y nombres de los implicados en la captura de Valentín. La mayor exactitud y familiaridad aparece en la versión 1, lo que da indicios de una versión primigenia, en la que la función noticiera está presente, pues aparecen concretamente los nombres de lugares y las personas que acompañaban a Valentín, como indicios para fundar la verosimilitud. Con todo, las variantes muestran vacilaciones. Una de las versiones relata que los captores encontraron al protagonista sin mayor esfuerzo:

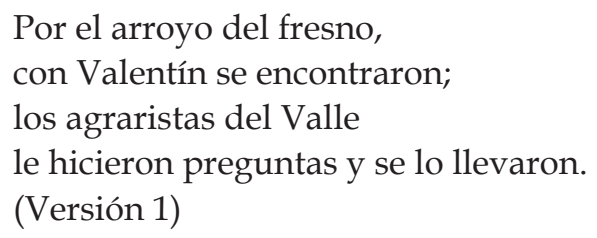

Por el arroyo del fresno, con Valentín se encontraron; los agraristas del Valle le hicieron preguntas y se lo llevaron. (Versión 1)

Sin embargo, otra versión cuenta que los del gobierno dieron con el paradero del cristero luego de una ardua búsqueda con todo e interrogatorio previo:

Fue un lunes por la mañana que en El Salto lo rastrearon; los agraristas del Valle, haciendo preguntas lo localizaron. (Versión 2)

En un intento por justificar una causa-efecto entre versiones, la facticia de Avitia consigna las dos estrofas, aunque en distinto orden como se presentan aquí.

Luego de la captura, todos se dirigen a comer, "en una fonda" (versión 1), y según la misma, se sentaron "en la mesa"; mientras 
que en otra, "llegaron a un jacal" (versión 2), y se sentaron "en el suelo". Este tipo de cambios, aunque mínimos, revelan un intento de adaptación a las realidades propias de cada lugar y un énfasis en la sencillez, pero también en la pobreza de las condiciones en las que se dio la lucha armada. Recordemos que, para que un texto sea recordado debe ser resignificado de acuerdo con ajustes que correspondan a los parámetros estéticos y formales de la comunidad. Abundando más, una de las versiones menciona a los presentes durante la comida, de los que sabemos, eran miembros principales:

Se fueron para una fonda

todos juntos a comer;

todo el Estado Mayor,

Epigmenio, Chon Salas, Valentín también.

(Versión 1)

Otra versión no especifica quiénes fueron, pero destaca cuántos eran aquellos miembros de importancia, así como el bando que representaban:

\author{
Llegaron a un jacal, \\ todos juntos a comer; \\ todo el Estado Mayor \\ cincuenta agraristas y un coronel. \\ (Versión 2)
}

Estas vacilaciones muestran un fenómeno importante: quienes fueron a la comida son personajes de relevancia - directamente se consigna al Estado Mayor - la versión del lugar de aprehensión nombra a los cabecillas, en tanto la versión 2, imprecisa, se contenta con señalar a cabecillas agraristas y un mando militar, pues para ese documento, los nombres no resultan significativos; tampoco interesa saber su función ni a qué intereses representan. En ese mismo lugar, según las versiones anteriormente citadas, se da el interrogatorio a Valentín y se crea una intriga, pues quien lo 
entregó fue "una mujer" (versión 2), o bien, "una vieja lo entregó" (versión 1). Luego de la captura de Valentín, antes (versión 1) o después (versión 2) de la mención de la mujer, hay una estrofa que revela el paso del prisionero y sus captores por el poblado de Huejuquilla. La referencia al lugar, aunque vacilante, menciona que en ese lugar o cerca de ahí, el gobierno aprehende a Valentín:

Se fueron pa`Huejuquilla

en... lo encontraron [sic];

el pobre de Valentín

se encontraba triste, muy desconsolado.

(Versión 1)

Otra versión tiene un sentido distinto: en el poblado no había gente armada que ayudara a liberar a Valentín, quien, ya aprehendido, pasó por el lugar:
Al llegar a Huejuquilla,
gente armada no encontraron;
el pobre de Valentín
se encontraba triste, muy desconsolado.
(Versión 5)

Otras versiones, ya con un valor noticiero menos fuerte, alcanzan un tinte novelesco que incrementa el interés narrativo: una mujer traidora que, junto con Valentín, pertenece a las mismas huestes de Quintanar, delata a Valentín antes de su paso por ese lugar:

Muy antes de Huejuquilla,

la mujer lo señaló;

iba con unos arrieros,

y en eso la tropa llegó y lo cercó.

(Versión 2) 
La versión octava, interpretada por Lucha Villa, de las más breves, coloca el trayecto por Huejuquilla en otro segmento narrativo: justo antes de que Valentín, cuando se despide y asume su destino desgraciado, se encomiende a la Virgen. El poblado es aquí un lugar de paso. A diferencia de las estrofas anteriores, ésta posee una síntesis asombrosa y efectiva, pues anticipa su condena:

\author{
Pasaron por Huejuquilla, \\ con Valentín amarrado, \\ leyéndole la sentencia \\ que llegando al cerro iba a ser fusilado. \\ (Versión 8)
}

Esta cuarteta integra una valiosa información en cada verso: el lugar, cómo era llevado el protagonista, lo que hacían sus captores y su destino fatal. Si bien la narración es preponderante en el corrido, la presencia de algunas estrofas con información precisa como presenta la variable de Huejuquilla acercan el corrido a una función noticiera que precisa los detalles, y conserva su nexo con el ámbito particular donde - posiblemente - se desarrolló la historia o una parte significativa de ella. Sin embargo, la presencia de otros factores circunstanciales de la narración, como la manera en que aprehendieron a Valentín, quiénes estuvieron presentes y el sitio donde los capturaron o pasaron con él aprehendido, siguiendo la lectura de todas las variantes, es inestable. Si hacemos caso de aquella afirmación de Ramón Menéndez Pidal en cuanto a que la comprensión del texto está en el conjunto de sus versiones, encontramos que estos datos precisos muestran vacilaciones porque no mantienen sistemáticamente su significado a lo largo de la secuencia, aunque no hay un cambio de sentido en los núcleos narrativos, muy al contrario, algunas variantes, como en caso de las versiones 2 y la 8, interpretada por Lucha Villa, tienden a la síntesis novelesca, con énfasis emotivo en la traición y la tragedia que se avecina para el héroe. 


\section{Las tres preguntas}

Luego de su captura, viene a continuación la resistencia heroica de Valentín, quien es interrogado tres veces - marca tradicional, tanto en las versiones cantadas (de la 6 a la 9) como en la versión larga (3). En dos de las versiones más largas, las preguntas ascienden a cuatro (versiones 1 y 2). La indeterminación de los agentes del gobierno que se había evidenciado antes permanece en esta secuencia: las variantes presentan soluciones distintas en cuanto a quién o quiénes lo interrogaron si bien en todas ellas son personajes con rango militar. En este aspecto, las versiones no carecen de observaciones de interés que apuntan hacia una presentación imaginativa, plenamente intencional. En la versión 1 quien pregunta es "el general", lo mismo que la versión 7, cantada por Vicente Fernández. La versión 2, lo mismo que otras, alterna entre un plural impersonal, "le empiezan a preguntar" y la presencia del "capitán" quien hace el resto de las preguntas. La versión 8 de Lucha Villa menciona únicamente al "coronel". La versión 9 de Amparo Ochoa menciona en dos ocasiones al general y una al coronel.

La versión 3, lo mismo que la 6, cantada por Antonio Aguilar, son interesantes porque generan una tensión in crescendo en la que, en orden ascendente de rango, un capitán, un coronel, y un general, formulan una pregunta al héroe cautivo, aunque el último, que forma parte de la categoría militar más alta, prueba al máximo la lealtad del rebelde cuando le ofrece el indulto. Desde luego, esta secuencia de tentación, presentada de modo artificioso, alude figurativamente a Cristo quien, en el desierto, también tres veces, fue tentado por Satanás en momentos de vulnerabilidad y no claudicó. Esta presencia religiosa, entretejida en la historia, evidencia la filiación del corrido, en un entorno en el que las virtudes, la valentía y la fidelidad aparecen bajo la ideología del catolicismo, característica de la lucha cristera.

Por otra parte, en esta secuencia lo relevante es caracterizar a Valentín como un personaje fiel a sus ideales y correligionarios, además, de sugerir la razón por la que lo ajustician. El 
héroe no da indicio alguno que lleve a la captura de un sacerdote o de quien protege a los ministros de la fe.

Las preguntas presentan modificaciones. La versión corta del corrido, que ha quedado como vulgata - o versión privilegiada según aseguró Vicente T. Mendoza en uno de sus libros, cuenta lo siguiente:

El capitán le decía:

- ¿cuál es la gente que mandas? -

- son los doscientos soldados

que tienen sitiada la hacienda de Holanda

El coronel le decía:

- ¿cuál es la gente que guía? -

- son los doscientos soldados

que trai por la sierra Mariano Mejía.

El general le decía:

- yo te concedo el indulto, pero me vas a decir cuál es el jurado y la causa que juzgo. (Versión 6, Antonio Aguilar)

De acuerdo con las interrogantes, Valentín encabeza entre "quince soldados" (versión 1), "treinta y nueve bragados" (versión 2), "doscientos soldados" (en la versión 6, en voz de Antonio Aguilar), hasta los hiperbólicos "ochocientos soldados", en las versiones de Vicente Fernández (7), Lucha Villa (8) y Amparo Ochoa (9); cuya última variante intensifica el carácter de la insubordinación, en vez de soldados, son "alzados". Una de las estrofas, repetida en varias versiones, menciona ambiguamente "la gente está afortinada" (versiones 1, 3 y 4). Todas estas variantes evocan el carácter popular y disidente de la insurrección cristera.

La respuesta en la que Valentín menciona a "la hacienda de Holanda" aparece en la mayoría de las versiones (1, 5, y las interpretaciones de Antonio Aguilar (6), Vicente Fernández (7) y Lucha Villa (8); en tanto que el "Rancho de Olanda" está presente en la 
versión 3; la versión 2, reproduce "el potrero llamado "Los Andas" y Amparo Ochoa canta "el rancho de los Landa", esta última versión, al parecer, coincide con los sucesos históricos que inspiraron el corrido, pues "los Landa eran ricos terratenientes" (Meyer, 1986: 163) de la zona. Sin embargo, esto no significa que otras denominaciones sean erróneas desde el punto de vista de la tradicionalización: estas versiones evidencian que los receptores y posteriores cantores del corrido no conservaron un dato histórico que no tenía sentido ni pertinencia para ellos, pues en un entorno tradicional se conserva lo que tiene valor para ser difundido. Lo importante para el transmisor, según la lectura que se desprende de las versiones, es resaltar que las huestes de Ávila eran pocas y efectivas o eran numerosas y tuvieron sitiado un lugar y, en ese sentido, da igual si era una hacienda o un rancho. Por supuesto, menos importancia tiene el nombre de aquel espacio.

La pregunta planteada a propósito de los soldados que dirige Mariano Mejía es constante en el corpus: aparece sin cambios en todas las versiones. Es muy posible que el nombre de aquel jefe cristero haya quedado lejos de una vinculación con aquel suceso. Mariano Mejía "fue un mestizo de sangre cora que para la causa cristera alzó gente de la serranía nayarita" (Meyer, 1986: 162). Sin embargo, difícilmente un oyente, alejado en el tiempo y el espacio de los eventos históricos podría saber quién fue Mariano Mejía; lo más probable para la mayoría de los receptores es que aquel nombre no corresponda a una realidad histórica, y se presente como una figura convencional cuyo apellido funciona dentro de la rima de la cuarteta.

Hay que resaltar que a partir de esta secuencia, hay una actualización dramática de los personajes, que hablan por sí mismos en tiempo presente: a partir de este momento, el narrador les concede voz y la historia que sucedió en el pasado se representa al mismo tiempo que se cuenta, es decir, adquiere performatividad.

En esta cuarteta existe la posibilidad de que la versión cuyo verso interroga "cuál es el curato y la casa de Justo" sea la más apegada al entorno de la Guerra Cristera donde se originó el 
corrido, es lógico que en tiempos de supresión del culto religioso las tropas buscaran alguna casa parroquial y a algún sacerdote que oficiara misas en secreto. Según Jean Meyer, el corrido se refiere a un tal "Justo Jaime, hombre rico y muy católico que favorecía a los rebeldes" (Meyer, 1986: 161). En el contexto de las preguntas que se le hacen a un reo, a largo plazo las palabras jurado y juzgar permanecen vigentes, no así curato y justo, que remiten, la primera, a la guerra cristera y la segunda, a un nombre propio de referencia inmediata, pero que se pierde a través del tiempo $(5,6,7$ y 9):

Pero me vas a decir cuál es el jurado y la causa que juzgo.

(Versión 6, Antonio Aguilar)

La versión que Lucha Villa (8) canta dice “cuál es el jurado y la causa que busco". Otras versiones presentan variantes con palabras que suenan similares, pero no hay una decodificación plena. Es decir, estamos ante una estrofa en la que se reconocen versos que no fueron operativos para el transmisor, o fueron cambiados a propósito para la parodia, que a la larga fue la que se conservó. Como bien apunta Paul Bénichou: "es costumbre de la poesía tradicional aceptar incoherencias materiales y resolverlas abriendo nuevas perspectivas" (Bénichou, 1968: 56) tal como sucede en este caso. Una vez más, se constata que la versión corta, más conocida, pierde su dimensión histórica y su densidad léxica, con tendencia hacia la síntesis. No obstante, la economía de la abstracción mantiene el sentido original de la composición sin perderse en los detalles irrelevantes.

Es importante señalar que hay alteraciones en el orden de esta presentación en relación con las otras. No siempre aparecen las tres preguntas en la misma escena. En la tercera versión de este corpus se crea suspenso cuando luego de las preguntas, el transmisor regresa a la segunda sucesión narrativa, informando los pormenores de la captura de Valentín. Puede ser también, que entre las dos primeras preguntas y la tercera esté la 
estrofa que anticipe que Valentín no responderá, como en la segunda versión.

El esfuerzo por caracterizar la resistencia y lealtad de Valentín provoca que las preguntas y las tentaciones como el ofrecimiento de dinero vuelvan una y otra vez antes de la muerte del protagonista:

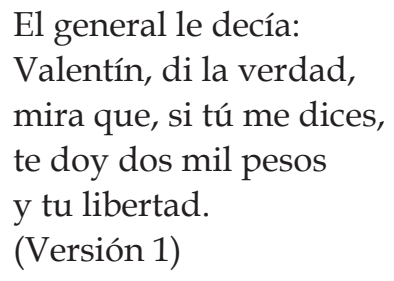

E incluso, sobreviene el ofrecimiento de un caballo para marcharse, libre de toda acusación:

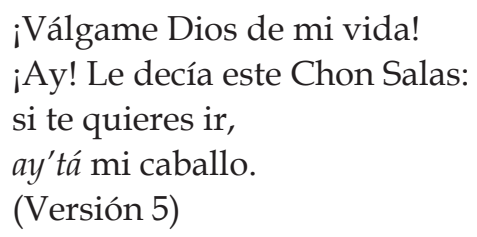

Se reiteran los ofrecimientos en la versión 1, y las preguntas incluso luego de que Valentín ya se despidió y sabe que su muerte es inminente, como en la versión 2. Como dije anteriormente, las versiones sintéticas de ocho estrofas siguen cabalmente el orden de las secuencias, y es que en estas versiones cortas se conservan las estrofas nucleares. Hay otras partículas que son satélites y pueden moverse incluso entre secuencias, pero en la búsqueda de lo nuclear, son prescindibles.

Aunque este breve trabajo no puede detallar en su totalidad las versiones más cortas, quisiera señalar que las ocho estrofas de la versión vulgata son precisas: poseen una condensación y calidad poética asombrosas, pues conservan fórmulas típicas del género y modos de habla regionales. Son efectivas narrativamente 
hablando y no se dilatan en descripciones, ya que por medio de acciones caracterizan al personaje y se sobreentienden actitudes y valores implícitos. Todo ello se incorpora en función de un solo sentido que orienta todo el conjunto hacia una misma finalidad. Se aprecian todos estos recursos que he mencionado y, como en un vórtice, su fuerza y su preeminencia van modelando la composición, dejando unos elementos, potenciando otros y repeliendo otros más, hasta llegar a una definición impecable. "En este sentido, el texto más novelesco, con personajes absolutamente ficticios puede adquirir un valor de verdad, una referencialidad histórica para la comunidad cuando ésta siente que el lenguaje y el estilo, en nuestro caso del corrido, como propio y en el cual puede volcar su sistema comunitario de valores" (González, 1999: 96).

\section{La negativa de Valentín}

De las tres preguntas que le formula la autoridad, Valentín responde dos. No contesta el tercer cuestionamiento, muy al contrario, el capturado se jacta de su hombría. La estrofa de la versión vulgata y todas - excepto la facticia -, dice así:

Valentín como era hombre,

De nada les dio razón:

"-Yo soy de los meros hombres,

que han inventado la Revolución".

El orden de esta cuarteta suele situarse al final de las tres preguntas, como cierre del narrador que comprueba la lealtad del héroe; o se sitúa entre la segunda y la tercera, para recalcar la negativa del protagonista y conseguir una mayor tensión dramática. Esta estrofa tiene cierta movilidad, pero su función es central y, por ello, suele situarse justo antes de la muerte de Valentín. En este sentido, otras estrofas, como las descriptivas, son prescindibles.

Hay otro fragmento en el que Valentín, tentado por el ofrecimiento de un caballo para irse libre si delata a sus compañeros, 
reitera su silencio y defiende su lealtad con la vida. Esta cuarteta aparece en versiones largas, solamente la versión 1 carece de la cuarteta anterior.

Le contestó Valentín:

-Eso no lo puedo decir,

prefiero el que me maten,

yo por un amigo prefiero morir.

(Versión 1)

La interpretación de Amparo Ochoa incorpora una estrofa en la que Valentín, muy resuelto, niega toda posibilidad de entregar a sus amigos. En las otras versiones la aseveración tajante está en voz del narrador, en ésta hay un Valentín arrojado y bravucón:

Valentín con gran valor le dijo así al general:

- De la gente que yo traigo

a ninguno de ellos le voy a entregar.

(Versión 9, Amparo Ochoa)

\section{Despedida e invocación a la Virgen de Guadalupe}

En el corrido no aparecen las palabras de ningún miembro del gobierno sentenciando a Valentín; la composición alcanza gran patetismo cuando el protagonista asume que su destino es la muerte. En ese momento, el narrador expresa los sentimientos del héroe, que invoca a la Virgen de Guadalupe. Es de suma importancia el profundo simbolismo que tiene esta advocación mariana en la cultura mexicana: la más alta representación del amor y la intercesión divina y, a la vez, el símbolo religioso que unificó al país. El grito cristero era “¡Viva Cristo Rey! ¡Viva la Virgen de Guadalupe!” (Meyer, 1973: 123). Y, aunque teñida por otras implicaciones, la presencia de la Guadalupana en este corrido es un símbolo de la causa cristera. Puedo mencionar 
también que la Virgen de Guadalupe, como exclamación de patetismo y emotividad, aparece también en el corrido cristero de Carlos Coronado cuando éste es asesinado:
Decía don Jesús Valles, como queriendo llorar - ¡Madre mía de Guadalupe que no vaya a despertar!
(Razo Oliva, 1983:37)

Mediante el sacrificio voluntariamente asumido, Valentín conjunta valores regionales y religiosos unidos en una estética colectiva y una sensibilidad comunitaria. Este es un factor fundamental que explica la vitalidad y vigencia del corrido, pues el texto perdura mientras tiene elementos que expliquen los valores de una sociedad, que permanecen a pesar de que las condiciones políticas hayan cambiado. Cada comunidad conoce el tipo de principios que son operativos y en el caso de Valentín, se elogia su entereza y determinación absoluta. Ese tipo de valores, sin duda, no necesitan una certeza histórica:

De este tipo de personajes [los caudillos de la Revolución] importa más decir las acciones (o el significado propagandista de sus acciones) que definirlos como héroes. También de las revueltas cristeras de la segunda y tercera décadas del siglo pasado surge una serie de personajes que en la imaginación popular alcanzaron la dimensión de héroes extraordinarios por su valor, orgullo u osadía. Entre estos personajes históricos se pueden mencionar al padre Peñaloza, al general Goroztieta y a Trinidad Castañón, pero destacan Victoriano Ramírez [...] y Valentín Ávila, famoso en los corridos como Valentín de la Sierra, a quien se le atribuye el valor a toda prueba y la dignidad ante la muerte, rasgos característicos del personaje novelesco (González, 2015: 179).

La estrofa que cuenta la invocación a la Virgen de Guadalupe es nuclear en el corrido pues se conserva en siete variantes: 1, 3, 
y en las de los intérpretes Antonio Aguilar (6), Vicente Fernández (7), Lucha Villa (8) y Amparo Ochoa (9):
Antes de llegar al cerro
Valentín quiso llorar:
- "Madre mía de Guadalupe,
por tu religión me van a matar".

En la versión 2 hay una variación de la estrofa en la que la invocación es un lamento puesto en voz de una líder revolucionaria: "Al pasar por charco/ Tiva comenzó a gritar". (Esparza, 1976: 110). Efectivamente, Tiva era el hipocorístico de "María Natividad G. González, llamada "la generala Tiva", la tesorera de la Brigada Quintanar" (Meyer, 1976: 24) La voz de Tiva en el corrido resalta el apoyo y el dolor de la comunidad por la muerte del cristero. Este lamento en voz de mujer resulta efectivo y de profunda repercusión estética en el mundo hispánico, pues evoca la tradición de la endecha, que lamenta la muerte de un personaje o la desgracia de una comunidad. Por otro lado, la versión que deja al valiente solo y vulnerable frente a la divinidad no es menos impresionante, pues adquiere una dosis de patetismo que humaniza al personaje.

Esta secuencia de despedida del protagonista tiene amplias posibilidades de desarrollo para los transmisores, pues la caracterización del héroe y su actitud ante la muerte ofrecen la ocasión única de ensalzar a Valentín frente a la adversidad añadiendo numerosas precisiones emotivas. Valentín dice adiós amargamente:

Lo llevan para la sierra

a hacerle la ejecución.

"Ya me voy con los del Valle,

adiós mis amigos, adiós ya me voy".

(Versión 1)

En otra variante de la misma estrofa, Valentín se despide de un personaje específico, que bien puede ser Enrique Gorostieta, 
un liberal partidario del régimen de Porfirio Díaz, formado en el Colegio Militar, y que entró a las filas cristeras tiempo después de la caída del dictador (González M., 2001: 148). O bien podría ser, como ya se ha visto, una figura convencional:

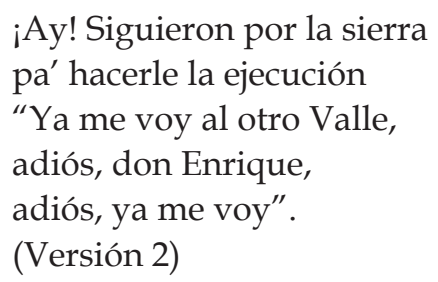

La versión más larga del corrido es la que reconstruyó Antonio Avitia. Como mencioné al principio de este trabajo, supuestamente la versión "original" del corrido cantaba la traición de Valentín. Avitia, según los datos históricos que ha recopilado, formuló una reconstrucción que supone cómo habría sido aquel corrido inicial. Según el texto propuesto por el estudioso, el cambio de un héroe a un traidor se lleva a cabo en pocos versos. En vez de la estrofa que en todas las versiones dice:

Valentín como era hombre, de nada les dio razón:

yo soy de los meros hombres, que han inventado la Revolución.

La versión facticia es contraria a la rima y la estética colectiva:
Valentín muy asustado
de todo les dio razón:
"Por una ofensa que tengo
de Ignacio Serrano me quiero vengar".
(Versión 4)

Según la versión confeccionada por Avitia, luego de esa respuesta nadie confía en el traidor Valentín. Los del gobierno lo miran con recelo: 
Luego que les dijo esto

se vieron unos a otros:

"Si esto lo haces con aquellos

mañana o pasado

lo harás con nosotros". ${ }^{4}$

(Versión 4)

Tal como sucede en el corrido tradicional, Valentín se niega a decir dónde está el curato de "Justo" y en ese momento, el corrido reconstruido de Avitia regresa a la estructura original hasta el cierre, en el que también coinciden las versiones tradicionales. En vez de cantar el conocido:

Vuela, vuela, palomita, párate en aquel fortín. Estas son las mañanitas de un hombre valiente que fue Valentín.

La versión reconstruida compone lo siguiente:
Vuela, vuela, palomita, párate en aquel jazmín.
Éstas son las mañanitas de un hombre traidor que fue Valentín. (Versión 4)

Esta variante es la única que cambia el carácter leal de Valentín a su causa y a sus amigos. Hasta donde pude indagar, no se mantiene en la memoria colectiva aquella versión paródica que, según afirma Jean Meyer, es muy cercana a la primigenia y la que Avitia intentó reproducir. Este corrido facticio, aunque maneja las secuencias de modo adecuado, no tiene procesos de tradicionalización, no sólo porque obedece a criterios compositivos

\footnotetext{
${ }^{4}$ Tal como se consignó, la versión facticia de Avitia está escrita en quintillas.
} 
que pretenden reconstruir históricamente un acontecimiento, sino porque tampoco el autor maneja los recursos propios de la tradición, y cantar la traición de Valentín al margen de una cultura comunitaria no tiene sentido identitario.

La versión cantada por Amparo Ochoa presenta un insólito cariz distinto cuando Valentín sabe su destino. Sin ningún antecedente, la bravuconería desafiante del protagonista ante su muerte lo acerca a la actitud del bandolero.

Se paseaba y se sonría [sic]

antes que lo fusilaran

- ¿Qué esperan que no me matan?

¡Denle al corazón, no apunten a la cara!

Cuando ya cayó en el suelo,

Sólo dijo estas palabras:

- ¡Madre mía de Guadalupe,

a tu amado hijo encomiendo mi alma!

Así como se sonría [sic], muerto se quedó sonriendo,

y toditos se admiraban de él por su valor, que era tan tremendo.

(Versión 9)

Sobra decir que esta actitud fanfarrona entra en conflicto con aquel Valentín sereno, que ha aparecido aquí en otras variantes. Al mismo tiempo, la petición de recibir los disparos en el pecho y no en el rostro es característico de dirigentes revolucionarios. Desde mi punto de vista, no es aventurado suponer en esta parte un cruce con los corridos de bandoleros que adscriben a Valentín de la Sierra a una filiación novelesca, pues en este tipo de cruces, un texto contamina a otro y este factor lleva aparejadas ciertas incoherencias, que en este caso se pueden ver en la actitud del protagonista ante sus verdugos. Esto no resulta extraño en la estética del corrido. "El gusto popular tiende más frecuentemente a caracterizar como héroes con los 
rasgos de valentía, arrojo, orgullo, etc., a otros personajes revolucionarios que podríamos considerar como secundarios e incluso con una dimensión histórica más bien confusa o ideológicamente poco definidos" (González, 1999: 91). Con todo, hay que señalar que ésta no es la tradición dominante del corrido, sino una posibilidad.

La actitud desafiante de mantener la sonrisa aun después de muerto, ante el azoro de sus adversarios, es totalmente distinta de la que presentan otras versiones, en las que la dignidad mostrada por el héroe conmueve a sus mismos enemigos después de su ejecución. Las versiones nuevamente oscilan entre aludir a un capitán (versión 1) y a un oficial (versión 2), quienes se duelen de la desgracia del leal y valiente cristero:

Del pobre de Valentín

un capitán se dolió,

lo montaron en un macho

y en él lo llegaron

a donde murió.

(Versión 1)

\section{Cierre del corrido}

La despedida de la pieza tiene una solución formulaica que compendia el sentido de la composición. Cantar las mañanitas de un valiente significa actualizar y hacer vigente su historia para el futuro. "Este valor es reconocido por sus propios enemigos y el narrador se encarga de subrayar esta característica en las despedidas tópicas del corrido, dándole con ello un valor de objetividad y de reconocimiento a la voz popular" (González, 1999: 88). Las versiones tradicionales cuentan:

Vuela, vuela palomita, párate en aquel fortín. Estas son las mañanitas de un hombre valiente que fue Valentín. 
Tanto el "vuela, vuela, palomita" y "las mañanitas" son despedidas típicas del corrido. Otra composición que mantiene semejanzas con el de Valentín de la Sierra es el de Benjamín Argumedo, que ubica al final el famoso:

$$
\begin{aligned}
& \text { Vuela, vuela, palomita, } \\
& \text { párate en ese romero } \\
& \text { estas son las mañanitas } \\
& \text { de Benjamín Argumedo. } \\
& \text { (Mendoza, 1954:162) }
\end{aligned}
$$

\section{Conclusión}

Valentín de la Sierra es un ejemplo de corrido tradicional en muchos sentidos. Conserva un principio y un final formulaicos y la estructura cuartetística propia de este prestigioso género de balada mexicana. En las versiones que se analizaron, se reconocen diversos procesos de tradicionalización: hay variantes mínimas hasta versos que no son operativos para el transmisor y fueron cambiados por versos cuya decodificación de sentido no es plena o es una adaptación a las condiciones de su contexto. Las versiones más largas presentan desarrollos narrativos con información contextual cuya función noticiera desaparece en las versiones más cortas - como la vulgata -, que sintetiza el corrido y lo coloca en una función novelesca, donde existe una indeterminación temporal y espacial que surge de la pérdida de sus nexos con su ámbito particular. Otro rasgo de tradicionalización presente en los desarrollos narrativos consiste en la alteración en el orden de las secuencias que provocan perspectivas distintas y funcionalidades divergentes, como puede ser una que privilegia la función noticiera; otra que incrementa el suspenso; una más que es fundamentalmente novelesca y ha perdido su densidad léxica, y una preeminencia de la narratividad basada, más que en descripciones, en las acciones del héroe por medio de "combinaciones posibles: las que concuerdan con la intención profunda 
del poema, con lo que en él va sobreentendido y vale más que lo dicho" (Bénichou, 1968: 88). Y, como también explica Aurelio González, será la caracterización heroica, la novelización, el uso de un discurso codificado y una temática específica lo que hará que estos personajes alcancen trascendencia al permanecer en la memoria colectiva (1999: 96). Una de las versiones presenta un cruce con los corridos de bandoleros y cabecillas revolucionarios, con lo que la función novelesca se fortalece, aunque no es la tradición dominante.

Como se ha podido apreciar, cada una de las variantes presenta cambios que alteran el significado sin cambiar la lectura del discurso, esto implica creación bajo parámetros tradicionales. Aunque Paul Bénichou habló del Romancero, sus palabras bien pueden aplicarse a la balada mexicana, y en este caso, al corrido de Valentín de la Sierra:

Lo admirable es ver cómo se unen en ese tipo de creación, el uso pasivo de materiales preexistentes y la actividad delicadísima que tiende a recrear entre esos materiales, seleccionándolos, imponiéndoles los pequeños cambios necesarios y disponiéndolos con tacto, en una nueva cohesión afectiva y estilística [...] ese doble aspecto, pasivo y activo, de la creación tradicional, es, en el fondo, la ley de toda creación (Bénichou, 1968: 37-38).

Por otra parte, aunque no es el objetivo de este trabajo, para historiar las adaptaciones contextuales del corrido, en el análisis se resaltó la formación de una versión privilegiada o vulgata, conformada por ocho estrofas. Esta "versión" - si es que es posible fijarla - tiene muy pocas diferencias entre la versión 5 y las que interpretan los cuatro cantantes de música vernácula que conforman la segunda parte del corpus, identificada con las versiones 6 a la 9. Así, por medio de verbalizaciones, Antonio Aguilar intenta acercarse a sus oyentes, sin embargo, su versión, junto con la de Vicente Fernández y la de Lucha Villa presentan variaciones mínimas - alteración de orden en las preguntas, así como quién las hace: capitán, general, etc. -, cambios como busco 
en vez de juzgo, etc. Llama la atención el caso de la versión de Amparo Ochoa, porque, si bien formó parte de un movimiento folclórico universitario y culto, la última parte de su interpretación mantiene un cruce con los corridos de bandoleros.

De los múltiples aspectos de interés que mantiene este corrido, sin embargo, destaca el heró́smo como rasgo de identidad que a la comunidad le interesa preservar: un tipo del campo, devoto, leal a sus amigos de batalla, franco, resuelto y digno ante la inminencia de la muerte. Un tipo de hombre fundacional, no histórico, sino modelado por la tradición, cuyas hazañas se actualizan y se transforman en las comunidades que cantan su corrido.

\section{Versiones completas}

VERSIÓN 1

Voy a cantar unos versos de un amigo de mi tierra, del valiente Valentín que fue afusilado y colgado en la sierra.

No me quisiera acordar si era una tarde de invierno, cuando por su mala suerte, cayó Valentín en manos del gobierno.

En el arroyo del fresno con Valentín se encontraron, los agraristas del Valle, le hicieron preguntas y se lo llevaron.

Se fueron pa' Huejuquilla en... lo encontraron; el pobre Valentín 
se encontraba triste,

muy desconsolado.

Se fueron para una fonda

todo juntos a comer

todo el Estado Mayor,

Epigmenio, Chon Salas,

Valentín también.

Se sentaron en la mesa,

juntos con el general,

una vieja lo entregó

que era de la gente

de este Quintanar.

Le preguntó el general:

“¿Cuánta es la gente que mandas?”

"La gente está afortinada,

son quince soldados

del rancho de Holanda".

Le preguntó el general:

“¿Cuánta era la compañía?”

Son ochocientos soldados

que trae por la sierra

Mariano Mejía".

El general le decía:

"Valentín di la verdad, mira que, si tú me dices, te doy dos mil pesos y tu libertad".

El general le decía:

"Yo te concedo el indulto, pero me vas a decir

¿Dónde está el curato

y la casa de Justo?"

Le contestó Valentín:

"Eso no puedo decir, prefiero el que me maten, 
yo por un amigo,

prefiero morir".

Lo llevan para la sierra,

a hacerle la ejecución;

"ya me voy con los del Valle,

adiós mis amigos,

adiós, ya me voy."

Antes de subir al cerro

Valentín quiso llorar:

"Madre mía de Guadalupe,

por tu religión

me van a matar".

Al llegar al Charco Largo

le vuelven a preguntar:

“¿Quiénes son los levantados

de Higinio Madera

y Pedro Quintanar?"

Del pobre de Valentín

un capitán se dolió,

lo montaron en un macho

y en él lo llegaron

a donde murió.

Muévese este Valentín:

“¡Válgame Dios, ahora qué hago!”

Le contestó este Chon Salas:

"Si te quieres ir,

ahí está mi caballo".

Le pusieron una cruz

pa' no perderlo de vista,

para tener un recuerdo, queridos amigos

de los agraristas.

Vuela, vuela palomita 
de la torre hasta el fortín;

aquí se acaban cantando

los versos de Chon Salas

y de Valentín.

Irene Vázquez Valle y José de Santiago Silva. Corridos de la rebelión cristera. Cantado por Ángel Morales, voz y arpa, y Juan Manuel Morales, violín.

VERSIÓN 2

Voy a cantar un corrido

de un amigo de mi tierra,

llamábase Valentín

que fue afusilado

y colgado en la sierra.

No me quisiera acordar, que era una tarde de invierno cuando por su mala suerte cayó Valentín,

en manos del gobierno.

Fue un lunes por la mañana que en el salto lo rastrearon los agraristas del Valle, haciendo preguntas lo localizaron.

Llegaron a un jacal todos juntos a comer, todo el Estado Mayor, cincuenta agraristas y un coronel.

Se sentaron en el suelo, juntos con el capitán 
y una mujer lo entregó;

que era de la gente

de este Quintanar.

Muy antes de Huejuquilla,

la mujer lo señaló;

iba con unos arrieros,

y en eso la tropa

llegó y lo cercó.

En el arroyo del Fresno

le empiezan a preguntar:

“¿cuántos son los levantados

y dónde se encuentra

Pedro Quintanar?"

Valentín, como era hombre, de nada les dio razón.

"Yo soy de los meros hombres, los que han inventado la Revolución".

El capitán le decía:

"Valentín, di la verdad, mira que si tú me dices te doy tu caballo y la libertad".

Le contestó Valentín:

"Eso no puedo decir, prefiero el que aquí me maten, yo por un amigo prefiero morir".

¡Ay! Siguieron por la sierra pa' hacerle la ejecución, "Ya me voy al otro Valle, adiós, don Enrique, adiós, ya me voy". 

Al vadear por Huejuquilla gente armada no encontraron, el pobre de Valentín se encontraba triste y muy desconsolado.

Al pasar por Charco Largo Tiva comenzó a gritar: “¡Madre mía de Guadalupe por su religión lo van a matar!"

El capitán le decía:

“¿Cuál es la gente que mandas?”

“Dirá, la gente que guío;

está en el potrero

llamado Los Andas".

El capitán le pregunta:

“¿Cuánta es la gente que guías?”

"Son treinta y nueve bragados, que trai por la sierra

Mariano Mejía".

¡Ay! Le decía el coronel:

"Yo te concedo el indulto, pero me vas a decir ¿dónde es el curato y la casa de Justo?

Uno de los oficiales de Valentín se dolió, lo montaron en un macho y se lo llevaron hasta 'onde murió. Vuela, vuela palomita, de la torre hasta el fortín aquí termina el corrido 
de un hombre valiente que fue Valentín.

Cuauhtémoc Esparza Sánchez, recolección. Valparaíso, Zacatecas (Avitia, 1998).

\section{VERSIÓN 3}

Voy a cantar unos versos

de un amigo de mi tierra, del valiente Valentín, que fue fusilado y colgado en la sierra.

Ni me quisiera acordar era una tarde de invierno cuando por su mala suerte cayó Valentín

en manos del gobierno.

El capitán le decía:

“¿Cuánta es la gente que manda?"

"La gente está afortinada, son quince soldados

del Rancho de Olanda".

El coronel le pregunta:

“¿Cuánta es la gente que guías?”

"Son ochocientos soldados

que trae por la sierra

Mariano Mejía".

El general le decía:

"Yo te concedo el indulto, pero me vas a decir cuál es el jurado y la casa de Justo". 

Al llegar a Huejuquilla gente armada no encontraron, el pobre de Valentín se encontraba triste y muy desconsolado.

Se fueron para la fonda todos juntos a comer todo el Estado Mayor, Epigmenio, Chon Salas, Valentín también.

¡Ay! cuando estaban comiendo, una vieja lo entregó que era de la gente de Pedro Quintanar.

Lo tomaron prisionero lo pasaron por La Joya, allí murió un cabecilla de los consentidos del padre Montoya.

Salieron de Huejuquilla con Valentín amarrado, le leyeron la sentencia, que, subiendo al cerro, iba a ser fusilado.

“¡Válgame Dios de mi vida!", “¡Ay!" le decía este Chon Salas:

"Si te quieres ir ahí'stá mi caballo".

En la Loma del Carrizo le vuelven a preguntar:

“QQuiénes son los levantados?”

"Virgilio Madera

y Pedro Quintanar". 
Valentín como era hombre, de nada les dio razón:

"Yo soy de los meros hombres, que han inventado

la Revolución".

Antes de llegar al cerro, Valentín quiso llorar:

"Madre mía de Guadalupe por tu religión, me van a matar".

Don Epigmenio Talamantes, como es hombre adolecido, lo incorporó con su gente, porque él se acordara que era muy su amigo.

Vuela, vuela, palomita, párate en aquel fortín; aquí termina el corrido de un hombre valiente que fue Valentín.

Armando de María y Campos, recolección. Dolores Hidalgo, Guanajuato (Avitia, 1998).

VERSIÓN 4

Voy a cantar un corrido de un amigo de mi tierra, llamábase Valentín,

que fue fusilado y colgado en la sierra.

En un domingo de invierno ni me quisiera acordar, 
cuando por su mala suerte

cayó Valentín

en manos del gobierno.

Fue un lunes por la mañana, que en el Salto, lo rastrearon, los agraristas del Valle haciendo preguntas, lo localizaron.

En el Arroyo del Fresno con Valentín se encontraron, los agraristas del Valle, le hicieron preguntas y se lo llevaron.

Don Epigmenio Talamantes, como era hombre adolecido, lo incorporó con su gente, porque él se acordara que era muy su amigo.

Se fueron para un jacal, con todos juntos a comer: todo el Estado Mayor; cincuenta agraristas y un coronel.

Se fueron para una fonda todos juntos a comer, todo el Estado Mayor; Epigmenio, Chon Salas, Valentín también.

Se sentaron en el suelo, juntos con el capitán, y una mujer lo entregó que era de la gente de este Quintanar. 
Muy antes de Huejuquilla

la mujer lo señaló;

iba con unos arrieros

y en eso, la tropa

llegó y lo cercó.

En el arroyo del Fresno

le empiezan a preguntar:

“¿Cuántos son los levantados

y dónde se encuentra

Pedro Quintanar?"

El capitán le decía:

"Valentín, di la verdad,

Mira que si tú me dices,

te doy tu caballo

y tu libertad".

Valentín muy asustado

de todo les dio razón:

"Por una ofensa que tengo

de Ignacio Serrano

me quiero vengar".

El capitán le pregunta:

“¿Cuánta era la compañía?”

"Son treinta y nueve bragados

que trae por la sierra

Mariano Mejía".

El capitán le decía:

“¿Cuánta es la gente que mandas?”

“La gente está afortinada,

son quince soldados

del rancho de Los Landa".

Luego que les dijo esto,

se vieron unos a otros: 
"Si esto lo haces con aquellos, mañana o pasado lo harás con nosotros". ¡Ay! Siguieron por la sierra Pa' hacerle la ejecución: "Ya me voy al otro Valle, adiós, don Enrique, adiós, ya me voy".

Al vadear por Huejuquilla, gente armada no encontraron. El pobre de Valentín se encontraba triste y muy desconsolado. En la loma de Carrizo le vuelven a preguntar:

"¿Quiénes son los levantados?",

"Herminio Madera

y Pedro Quintanar".

Al pasar por Charco Largo

Tiva comenzó a gritar:

"Madre mía de Guadalupe, por su religión

lo van a matar".

Antes de llegar al Cedro, Valentín quiso llorar:

¡Ay! Le decía el coronel:

"Yo te concedo el indulto pero me vas a decir cuál es el curato y la casa de Justo". 
Le contestó Valentín

"Eso no puedo decir, prefiero el que me maten.

Yo por un amigo

prefiero morir".

Del pobre de Valentín

el capitán se dolió,

lo montaron en un macho

y en él lo llevaron

a donde murió.

Muévese este Valentín:

"Válgame Dios ¿Ahora qué hago?"

Le contestó este Chon Salas:

"¿Sí te quieres ir?

Ahí está tu caballo".

Le pusieron una cruz

pa' no perderlo de vista,

para tener un recuerdo,

queridos amigos,

de los agraristas.

Vuela, vuela, palomita

Párate en aquel jazmín

éstas son las mañanitas.

Versión reconstruida de Antonio Avitia Hernández (Avitia, 1998).

VERSIÓN 5

Voy a cantar un corrido

De un amigo de mi tierra

Llamádose Valentín

que fue fusilado y colgado en la sierra. 
No me quisiera acordar, era una tarde de invierno cuando por su mala suerte cayó Valentín en manos del gobierno.

El capitán le decía:

¿Cuál es la gente que mandas?

Son ochocientos soldados

que tienen sitiada la hacienda de Holanda.

El coronel le pregunta:

¿Cuál es la gente que guías?

Son ochocientos soldados

que trae por la sierra Mariano Mejía.

Valentín como era hombre, de nada le dio razón

- Yo soy de los meros hombres, de los que inventaron la Revolución.

El general le decía:

- Yo te concedo el indulto, pero me vas a decir cuál es el jurado y la causa que juzgo.

Antes de llegar al cerro, Valentín quiso llorar ¡Madre mía de Guadalupe por tu religión me van a matar!

Vuela, vuela palomita, párate en aquel fortín, estas son las mañanitas del hombre valiente que fue Valentín.

Quintín Zamora, informante. Dolores Hidalgo, Guanajuato, 18 de diciembre de 1950 (Mendoza, 1954). 
VERSIÓN 6

Voy a cantar un corrido

de un amigo de mi tierra

llamábase Valentín,

que fue fusilao y colgao en la sierra.

No me quisiera acordar, era una tarde de invierno cuando por su mala suerte cayó Valentín en manos del gobierno.

El capitán le decía:

¿Cuál es la gente que mandas?

Son ochocientos soldados

que tienen sitiada

la hacienda de Holanda

El coronel le decía:

¿Cuál es la gente que guías?

Son ochocientos soldados

que trai por la sierra Mariano Mejía.

El general le decía:

- Yo te concedo el indulto, pero me vas a decir cuál es el jurado y la causa que juzgo.

Valentín como era hombre, de nada le dio razón:

- Yo soy de los meros hombres, de los que inventaron la Revolución.

Antes de llegar al cerro, Valentín quiso llorar: - ¡Madre mía de Guadalupe, por tu religión me van a matar! 
Vuela, vuela palomita, párate en aquel fortín, estas son las mañanitas del hombre valiente que fue Valentín.

Antonio Aguilar (1968).

\section{VERSIÓN 7}

Voy a cantar un corrido de un amigo de mi tierra llamábase Valentín que fue fusilado y colgado en la sierra.

No me quisiera acordar, era una tarde de invierno cuando por su mala suerte cayó Valentín en manos del gobierno.

El general le decía:

“¿Cuánta es la gente que mandas?"

"Son ochocientos soldados que tienen sitiada la hacienda de Holanda".

Le vuelven a preguntar:

“¿Cuál es la gente que guías?”

"Son ochocientos soldados que trai por la sierra Mariano Mejía".

El general le decía:

"Yo te concedo el indulto pero me vas a decir cuál es el jurado y la causa que juzgo". 
Valentín como era hombre, de nada les dio razón:

"Yo soy de los meros hombres, que han inventado la Revolución".

Antes de llegar al cerro, Valentín quiso llorar:

"Madre mía de Guadalupe

por tu religión me van a matar".

Por el arroyo del fresno con Valentín se encontraron los agraristas del valle, le hicieron preguntas y lo desarmaron.

Vuela, vuela palomita, párate en aquel fortín estas son las mañanitas de un hombre valiente, que fue Valentín.

Vicente Fernández (2005).

\section{VERSIÓN 8}

Voy a cantar un corrido de un amigo de mi tierra llamábase Valentín Que fue fusilao y colgao en la sierra.

No me quisiera acordar, era una tarde de invierno cuando por su mala suerte, cayó Valentín en manos del gobierno.

El coronel le decía:

¿Cuál es la gente que guías?

Son ochocientos soldados que trai por la sierra Mariano Mejía. 
Le vuelven a preguntar:

¿Cuál es la gente que mandas?

Son ochocientos soldados

que tienen sitiada la hacienda de Holanda.

El coronel le decía:

yo te concedo el indulto,

pero me vas a decir

cuál es el jurado y la causa que busco.

Valentín como era hombre,

de nada le dio razón:

"Yo soy de los meros hombres,

de los que han inventado

la Revolución".

Pasaron por Huejuquilla

con Valentín amarrado,

leyéndole la sentencia

de que llegando al cerro iba a ser fusilado.

Antes de llegar al cerro,

Valentín quiso llorar:

“Madre mía de Guadalupe

por tu religión me van a matar".

Vuela, vuela palomita,

párate en aquel fortín,

estas son las mañanitas

dee un hombre valiente, que fue Valentín.

Lucha Villa (2002).

\section{VERSIÓN 9}

Voy a cantar un corrido

de un amigo de mi tierra, 
llamábase Valentín, que fue fusilado y colgado en la sierra.

No me quisiera acordar, era una tarde de invierno cuando por su mala suerte, cayó Valentín en manos del gobierno.

El general le pregunta:

¿Cuál es la gente que guías?

"Son ochocientos alzados que trai por la sierra Mariano Mejía".

El coronel le pregunta:

¿Cuál es la gente que mandas?

"Son ochocientos soldados

que tiene sitiado al rancho de los Landa.

El general le decía:

yo te concedo el indulto, pero me vas a decir cuál es el jurado y la causa que juzgo.

Valentín como era hombre, de nada les dio razón:

"Yo soy de los meros hombres, de los que inventaron la Revolución".

Valentín con gran valor le dijo así al general:

"De la gente que yo traigo, a ninguno de ellos le voy a entregar".

Antes de subir al cerro, Valentín quiso llorar: “Madre mía de Guadalupe por tu religión me van a matar". 
Se paseaba y se sonría antes que lo fusilaran:

“iQué esperan que no me matan?

Denle al corazón, no apunten a la cara!"

Cuando ya cayó en el suelo, sólo dijo estas palabras:

"¡Madre mía de Guadalupe,

a tu amado hijo encomiendo mi alma!"

Así como se sonría, muerto se quedó sonriendo, y toditos se admiraban de él por su valor, que era tan tremendo.

Vuela, vuela palomita, párate en aquel fortín estas son las mañanitas de un hombre valiente, que fue Valentín.

\section{Bibliografía citada}

Aguilar, Antonio, 1968. Banda sonora de la película Valentín de la Sierra, cinematográfica ABSA, dirigida por René Cardona, guion de Ricardo Garibay.

Avitia Hernández, Antonio, 1998. El corrido histórico mexicano, Voy a cantarles la historia (1924-1936). México: Porrúa, t. IV.

BÉNICHOU, Paul, 1968. Creación poética en el romancero tradicional. Madrid: Gredos.

ESPARZA SÁNCHEZ, Cuauhtémoc, 1976. El corrido zacatecano. Zacatecas: INAH-Departamento de investigaciones históricas/Universidad Autónoma de Zacatecas.

FERNÁNDEZ, Vicente, 2005. Álbum Vicente Fernández y sus corridos consentidos, Sony International. 
GonZÁlez, Aurelio, 1999. “Caracterización de los héroes en los corridos mexicanos". Caravelle: cahiers du monde hispanique et luso brésilien 72: 83-97.

, 2015. El corrido: construcción poética. México: El Colegio de San Luis.

GONZÁLEZ, Fernando Manuel, 2001. Matar y morir por Cristo Rey: aspectos de la cristiada. México: UNAM- Instituto de Investigaciones Sociales/Plaza y Valdés Editores.

MARÍA Y CAMPOS, Armando de, 1962. La revolución mexicana a través de los corridos populares. México: Biblioteca del INHERM, $\mathrm{t}$. II: 378-379.

MendozA, Vicente T., 1954. El corrido mexicano. México: Fondo de Cultura Económica, 202-203.

MeYer, Jean, 1973. La cristiada. 1- La guerra de los cristeros. México: Siglo XXI.

, 1986. "Valentín de la Sierra, historia de un mito". Relaciones 25: $157-164$

OcHOA, Amparo, 1995. Corridos y canciones de la Revolución Mexicana. México: Pentagrama.

Razo Oliva, Juan Diego, 1983. Rebeldes populares del Bajío. Hazañas, tragedias y corridos (1910-1927). México: Katún.

VÁzQUEZ VAlle, Irene y José de SANTIAGo Silva, grabación y selección, 2002. Corridos de la rebelión cristera, 4a. ed. México: INAH. Testimonio Musical de México 20.

VILLA, Lucha, 2002. Sus grandes corridos. Musart-Balboa. 